\title{
Social Responsibility for Health during COVID-19 Pandemic
}

\author{
- Dhana Ratna Shakya ${ }^{1} \bullet$ Ravi Ram Shrestha ${ }^{2} \bullet$ Sarun Koirala ${ }^{3}$ Santosh Upadhyaya Kafle ${ }^{4}$ Prasanna Subedi $^{5}$ \\ - Ayush Anand ${ }^{6} \bullet$ Aparna Ghimire ${ }^{1} \bullet K^{2}$ ishor Gurung${ }^{7} \bullet K^{\prime}$ rishna Pokharel ${ }^{8}$ \\ Submitted 19 January 2021 \\ Accepted 25 April 2021 \\ Published 30 June 2021
}

\# Dhana Ratna Shakya drdhanashakya@yahoo.com

(iD https://orcid.org/0000-0002-3796-5426

${ }^{1}$ Department of Psychiatry, BPKIHS, Dharan, Nepal

2 Department of Anaesthesia and Intensive Care, National Academy of Medical Sciences, Bir Hospital, Kathmandu, Nepal

${ }^{3}$ Department of Anatomy, BPKIHS, Dharan, Nepal

${ }^{4}$ Department of Pathology, Birat Medical College, Biratnagar, Nepal

${ }^{5}$ Intern, BPKIHS, Dharan, Nepal

${ }^{6}$ MBBS Student, BPKIHS, Dharan, Nepal

${ }^{7}$ Department of Microbiology \& Infectious disease, Nepalgunj Medical College, Nepalgunj, Nepal

${ }^{8}$ Department of Anesthesiology and Critical care, BPKIHS, Dharan, Nepal

"6

\section{Citation}

Shakya DR, Shrestha RR, Koirala S, Upadhyaya Kafle S, Subedi P, Anand A, et al. Social responsibility for health during COVID-19 pandemic. JBPKIHS. 2021;4(1):48-55

doi https://doi.org/10.3126/jbpkihs.v4i1.36091

\section{(c) (1) () $\Theta$}

This work is licensed under a Creative Commons Attribution NonCommercial 4.0 International License.
Health is a fundamental right for which concerned sides should bear the responsibility at the individual, societal, state, and international level. Not only curative but preventive, promotive, and rehabilitative services should also be availed in accessible, affordable, and acceptable form. The quest for health becomes more intense during adverse periods like a pandemic. The whole world has witnessed the COVID-1 9 pandemic, the unprecedented pandemic of this century. This quest is more dismal in developing nations like Nepal when even resource-rich countries are laid down by it. The quest of health demands, hence more during this pandemic, for the bearing of the responsibility by all. Here, we have made an attempt to draw together the general and some specific responsibilities of various direct stakeholders in this pandemic with multifaceted mayhem. We have incorporated here, the responsibilities of the public, COVID and non-COVID patients, media personnel, health science students, professionals, institutions, state, and media to ensure or safeguard the health of self and others in this pandemic.

Keywords: COVID-19 pandemic, Health, Nepal, Social responsibility

\section{Declarations}

Ethics approval and consent to participate: Not applicable Consent for publication: Not applicable

Availability of data and materials: Not applicable

Competing interest: None

Funding: None

Authors' contributions: DRS designed, compiled, drafted, rewrote and edited all sections. All other coauthors contributed to the respective sections (RRS- state, SK- public, SUK- professional, PS- students and trainees, AA- Social responsibility,AG -patients, KG- health organizations, KP- media).All authors have read and approved the final manuscript. Acknowledgement: None 
$\mathbf{S}$ ocial responsibility in the promotion of health was established as a priority at the World Health Organization Fourth International Conference on Health Promotion, in Jakarta [1]. This was based on the concept of social determinants of health. Social responsibility for health is defined as protecting the fundamental rights to the highest attainable level of health as an individual, group, and institution, and assisting within their means [2]. Health is a state of complete physical, mental and social well-being and not merely the absence of disease or infirmity [3].

Social responsibility and health are intertwined. A large population has no access to essential drugs and health services. Poverty, unethical international research practices, migration of health professionals to developed countries, transnational exploitation of the poor in organ transplant, and prevalence of VIP culture pose a major challenge in the application of social responsibilities in real-life scenarios [4].

Various stakeholders of life science service sectors have both the rights/ privileges and responsibilities for their welfare [5]. The government has the responsibility to uphold and protect the rights of its citizens and to provide the environment in which contributions of other sectors are amplified for the promotion of fundamental rights [4]. Physician's oath contained in the declaration of Geneva and the World Medical Association International Code of Medical Ethics enumerates the duties of medical practitioners. Health professionals should respect the autonomy of patients, with proper consideration of beneficence and non-maleficence and uphold the bioethical principles of non-stigmatization and non-discrimination while maintaining their privacy and confidentiality [5].

The private sector and industry hold the ethical responsibility to promote the shared interests of society which should follow relevant principles of justice and fairness [2]. Health science students have the responsibility to continue training, review, analyze and discuss current clinical cases, and to prepare themselves as future health professionals. Students also need to support the dissemination of scientific facts to inform the general population about disease prevention measures. Citizens have the responsibility to seek health services at all levels of prevention- promotive, preventive, curative, and rehabilitative efforts within the accepted framework of therapeutic relationship keeping respect to other stakeholders, mainly service providers. The WHO and other related international bodies bear the responsibility for cross-border solidarity and obligation to signatory countries for cooperation and collaboration for the health and welfare of humanity.

\section{COVID-19: A PANDEMIC WITH AN EXCEPTIONAL CHAL- LENGE}

COVID-19 was declared as a global pandemic in March, 2020 [6]. It affected almost all countries with a growing number of illnesses and death. Health (physical, psychosocial) and non-health sectors (education, economy etc.) were badly shattered [7-9]. The restrictive (e.g. lockdown) and other measures (e.g. testing) to control the disease led to a stressful situation [1012]. COVID-19 is primarily transmitted via respiratory droplets, contact routes, and aerosol-generating procedures. Human transmission among people in close contact (direct physical or face-to-face contact within one meter and for prolonged periods) when not wearing appropriate personnel protective equipment (PPE) occurs irrespective of the symptoms [13]. Despite the advent of vaccines, the importance of non-pharmacological interventions, infection control, and prevention measures can hardly be overemphasized to contain COVID-19 infection [6].

\section{STATE RESPONSIBILITY}

When definite treatment and effective vaccines are largely yet to be available, the main strategies are preventive modalities, especially in our country with limited health care resources. The major responsibilities of the state towards general public, non-health institutions and health care providers/ institutions are discussed below.

\section{A. TOWARDS GENERAL PUBLIC}

The state should share adequate evidence-based information through media to create a high level of awareness in the community and minimize fake news and conspiracies. Adequate provisions should be made for adopting infection prevention and control measures at home and work settings, including hand washing, basic hygiene, cough etiquette, and physical distancing. Universal access to public hand hygiene stations should be made and their use should be obligatory while entering or leaving any facility. Moreover it should monitor the public for their compliance to public health advices. Government should impose travel restriction from and within an infected region or zone and real-time surveillance of people at point of entry to country/ commu- 
nity through well-organized screening should be done for efficient case detection, rapid investigation of cases, and tracing of their contacts. There should be provision for quarantine for suspected cases with prompt access to health care [14-16].

\section{B. TOWARDS NON-HEALTH INSTITUTIONS}

The state should ensure public access to life-sustaining goods, safety, security and information while avoiding or limiting unnecessary gatherings. Essential life-sustaining goods and services should be made available in fixed time-bound manner with absolute public health precautions. Non-essential services should be shut down completely or with alternatives like work from home or online services. State should suspend all non-essential and crowd generating activities and services like education sector, international and domestic flights, conferences, seminars, gatherings, shopping malls, fitness and recreation centers, religious sites, and public vehicles. The decision to relax lockdown or restriction needs to be evaluated carefully and periodically [10]. Meanwhile, the state should provide various forms of assistance, packages, aids, and taxation/ other waivers to needy people.

\section{TOWARDS HEALTH CARE PROVIDERS AND INSTITUTIONS}

The government needs to protect the rights of health workers and bears the responsibility to implement the specific measures by following activities $[8$, 17]. The government should strengthen effective case detection and real-time surveillance for efficient case detection, contact tracing and quarantine should be done to interrupt transmission chains. It should focus on screening of cases based on clinical features, contact tracing and increase the number of testing by RT PCR method by investing on good PCR labs, enabling a high number of PCR tests wherever needed [11].

The government should develop the mechanism to promptly prioritize the cases according to symptoms. Severe to critical cases should be admitted to intensive care units with organ support facilities, moderate to severe cases in special observation wards with frequent monitoring and mild cases in isolation centers. Separate and designated COVID hospitals or hospital wing should be established. The government needs to build rapid response teams to respond to any sensitive and emergency cases. It should work for developing welltrained health care workforce and ensuring hospital beds, ventilators, oxygen, medicines and other medical logistics. Routine non-emergency medical/surgical services should be halted or limited at health care facilities while promoting telemedicine for such services whenever possible. At the same time, it should plan and implement the mechanisms to ensure critical and essential life-saving preventive and curative health services such as reproductive, maternal and child health services including antenatal care, deliveries, post-natal care and immunization, treatment of chronic diseases like diabetes, cardio-vascular, nervous system and kidney diseases, despite the health system being overwhelmed by COVID-19 [18].

The government should take the responsibility of providing adequate appropriate PPE, infection prevention and control, efficient medical logistic and supply chain management system to ensure all necessary preventive measures for health care providers to minimize occupational hazard and health risks. Moreover, it should emphasize on maintaining appropriate working hours with breaks for all working health workers and staffs, advising workers on self-assessment, symptom reporting and staying home when ill, providing access to mental health and counseling resources and building co-operation between management and workers [19]

\section{HEALTH PROFESSIONALS' RESPONSIBILITY}

Health workers are at the front line of the COVID-19 outbreak response and are exposed to hazards putting them at more risk of infection. Health professionals have to take care of self and also their family, clients and others to protect their health [20]. The WHO highlights both rights and responsibilities of health care providers simultaneously in relation to the COVID-19 pandemic [19].

Health workers should follow established occupational safety and health procedures so as to avoid exposing others to health and safety risks. Appropriate protocols should be used to assess, triage and treat patients. Patients should be treated with respect, compassion and dignity, also maintaining the patient confidentiality. It is the health care workers duty to follow established public health reporting procedures of suspect and confirmed cases and to help raise awareness, knowledge, and skills among public and other stakeholders (e.g. students, paramedics) regarding the health problem, including COVID-19. They should provide or reinforce accurate public health information on infection prevention and control to concerned people. It is also their responsibility to properly use, and dispose the personal protective equipment, self-monitor 
for signs of illness, self-isolate, and report the illness to their managers if it occurs.

The employers and managers of health facilities in turn need to ensure that all the necessary preventive measures are taken to ensure occupational safety and mitigate health risks. They should provide accurate information, instruction and trainings on occupational safety and health, adequate infection prevention and control measures, including sufficient quantities of personal protective equipment to all health care and other staffs involved in managing suspected or confirmed COVID-19 cases. They should maintain appropriate working hours with breaks for the staffs. They should advise the health workers on self-assessment, symptom reporting and home quarantine/ isolation when ill. Adequate mental health and counseling resources should be provided and a co-operation between management and workers and their representatives should be ensured.

\section{HEALTH INSTITUTIONS/ PRIVATE HOSPITALS RESPONSIBILITY}

Health institutions/ private hospitals have some unavoidable responsibilities for protecting health of people in COVID-19 pandemic. Private hospitals can subsidize the cost of tests, service charge or consultation fee for needy people during the pandemic. They can provide free services to marginalized people. This undertaking can lessen the burden of people as the entire nation has been experiencing economic stringency. If there are two hospitals nearby, one hospital can be used to solely take care of COVID-19 patients and the other one can be used to provide other general health care services. This may minimize the chances of spreading the infection. Regarding health institutions, if the administration could put a hold on fee submission for some time, it could provide some relief. Even if putting on hold is not possible, some more time at least can be given for the care. It is the responsibility of health institutions or private hospitals to organize enhanced real-time surveillance for efficient case detection, rapid investigation of cases detected and tracing of their contacts to enable isolation of cases and quarantine of contacts. They should help in conducting high number of PCR tests in standard PCR laboratories. They should ensure adequate number of PPE, hospital beds, ventilators and oxygen, medicines, medical logistics for admission and treatment of cases from moderate to severe for preventing case fatality. At the same time, they should ensure continuous quality critical and lifesaving preventive and curative health services like maternal and child care, geriatrics, etc. They should also ensure physical and psychosocial health of the service providers [21].

\section{HEALTH SCIENCE/ MEDICALSTUDENTS'RESPONSIBILITY}

With the adoption of restrictive and other measures to flatten the infection curve, both the government and common people face lots of consequent adversities/ difficult situations [22]. Most people are still ignorant about the nature of disease. Some are misguided by wrong information. People are afraid of visiting hospitals even for major problems [23] or they do not know about alternative strategies, e.g. telemedicine service, helplines [7]. They are vulnerable to mental health issues, including suicide due to pandemic, lockdown, or other factors prevalent during this period [24].

Students need to take care of self-health and help others and be a role model for ensuring health [25]. They can educate family members and neighbors about symptoms, transmission, and other information about the disease. They can make use of various media like videos, or social media to help decrease the misinformation prevalent in the society. They can actively get involved in providing counseling services by forming small groups, and conducting health awareness campaigns and helping local government in various of their activities. This may include educating and encouraging people about safety measures, identifying danger signs of diseases and helping such patients get appropriate health care, or counseling people to manage minor health issues at home. The students can also develop the skills of counseling on various health care and mental health issues.

\section{PUBLIC RESPONSIBILITY}

The ignorance and noncompliance of health rules among common people is a major factor for the transmission of disease. At a personal level, citizens need to break the transmission chain by maintaining physical distance and using personal protection measures, even when lockdown is relaxed $[10,26]$. Obeying the government strategic plans and guidelines (including restrictive measures) on part of the citizens and developing a conducive environment for public to follow them from government side pave way to success. Avoiding unnecessary crowds, wearing face masks properly, cel- 
ebrating festivals with the family members at home, restricting movements until it is urgent, using sanitizers, frequent handwashing, treating COVID positive people with empathy are new normal to be practiced [27]. The following nine-point tips have been followed in Wuhan, China intensively in relation to COVID-19 pandemic:

1. Being aware of and using mask in public places in a proper way

2. Washing hands with soap and water or sanitizer

3. Keeping a two-meter social distance

4. Reducing unnecessary travel or movements

5. Opening the windows

6. Conducting proper disinfection

7. Following a healthy diet

8. Keeping a healthy condition

9. Ensuring a healthy mentality, and not humiliating COVID positive people and motivating and supporting their families

During the pandemic, people need to adopt a form of self-leadership 'intelligent self-binding'. Self-isolation is a key component of any pandemic fight, i.e. act fast, isolate, break up social clustering, high self-esteem without panicking. While taking extra caution to maintain socio-cultural norms, the public should respect the autonomy and increase the morale of patients, doctors, nurses, and front-liners [28].

Citizens should practice the behaviors that help achieve a maximum physical, intellectual, and emotional health even during COVID-19 crisis. People should abide by the law and policy, because individual accountability is the essence of a good citizen which guides behaviors to best practices for living in current COVID-19 and future circumstances to a new normal [29].

The self-leadership of citizens must go together with government action to eliminate the contagion of the virus [28]. Due to COVID-19, the government has kept health at the top priority and civilized citizens must reciprocate it by showing the same commitment to responsibly and following safety instructions or measures [29]. People with a travel history should be urged to be in a quarantine facility or be in self-quarantine at home. While in common places like quarantine shelters, citizens should strictly follow discipline and disciplinary action should be implemented, e.g. those misbehaving with females should be punished.

\section{PATIENTS' RESPONSIBILITY}

Consumers of health services require assistance, facilitation, or some sort of address from health care providers [5]. Due to the present COVID pandemic, healthy members of society also need to assume a sick role in some form; meaning that they cannot continue their daily living in the normal way and need to behave as potentially infected to break the transmission chain [30]. Despite the advancement in the medical field, this virus has proven as difficult to be contained and life-threatening for vulnerable groups. This is the era of modern medicine where patients' autonomy is at the center of any therapeutic relationship. The current situation has, however, changed this focus into prioritizing the matters of public health over one individual. Hence, our therapeutic approach has slightly shifted its paradigm towards a more authoritative paternalistic model where certain behaviors are desired from treatment seeking individuals and there is less room for non-adherence to the policy of the healthcare system. This pandemic has put the role of ethical responsibility and moral duties of patients into perspective. Containing the spread of disease and managing patients within limited resources is already a herculean task. If any single unit of society puts its own privilege over his duty or breaches the infection control protocol, the task is impossible. The ethical responsibility of patients is one of the most important yet overlooked issues for effective management of the disease. We have enlisted some of the responsibilities of patients [31-33], both COVID and non-COVID, in the current pandemic situation as the following.

Strict self-isolation in addition to exclusive and explicit respiratory hygiene should be followed. Patients should monitor their own symptoms and seek early treatment. While seeking treatment they should let their COVID status be known upfront. If it is unknown and there are reasons to suspect, they should ask to get the test done first. They should also let the doctor know a detailed medical history, past history, treatment history including alternative medicine and the information for contact tracing truthfully. They should follow the instruction given by doctor as it is, avoid taking nonprescription unnecessary regime as well as avoid visit to hospital unless required, also don't miss follow-up appointments. They should follow specific hospital protocol for seeking treatment for other medical issues as well. Sometimes, other medical issues can wait till patient recovers from COVID-19; they 
should listen to and trust the doctors. They should follow the hospital rules for transmission prevention- social distancing, wearing mask, hand hygiene etc. If they get admitted in a COVID hospital they should follow the rules and regulations of hospital and express concern to health authorities calmly and clearly. They have to consider that there may be patients more severe and trust the health care workers and behave respectfully. Kindness from the patients can make a big difference.

While visiting hospital for non-COVID related issues, the infection control measures (mask, hand hygiene, respiratory hygiene, social distancing) should be embraced. They should take appointment beforehand so as to minimize their stay in hospital settings. They should be truthful and inclusive in history regarding COVID like symptoms or history of exposure and maintain a safe physical distance unless the attending doctor instructs otherwise. They should embrace telemedicine services as far as possible in addition to refraining from requesting unnecessary investigations and interventions. They should also be proactive for prevention of diseases, be adherent to the treatment and follow up schedule.

\section{MEDIA RESPONSIBILITY}

Media is a means of mass communication. Social media facilitates rapid sharing of messages through virtual networks. More than 2.9 billion people extensively use social media like: Facebook, Instagram, YouTube, WhatsApp, Viber, Zoom, WeChat, Twitter [34]. They disseminate information and raise awareness and literacy. However, inappropriate media activities (both process and content) spread misinformation, create havoc, and may lead to psychological trauma, anxiety and even suicide [35].

In an adverse situation like a pandemic, people depend on media even more. COVID-19 pandemic has resulted in an exponential increase in screen time for everyone. Hence, media is a powerful tool to disseminate information and change people's knowledge, attitude, and behavior. It can strongly influence in containing COVID-19 and saving lives [36]. However, a pressing problem with modern-day media is the spread of misinformation [36]. Inappropriate media activity can lead to minor problems like WhatsAppitis [37] to grave consequences like Werther effect [35, 38]. A recent study found that $27.5 \%$ of the most watched YouTube videos about COVID-19 included misinformation, reaching 62 million views globally [39]. Such falsehoods may engender widespread public anxiety and mental health problems [40], life-threatening self-medication and non-compliance with COVID-19 measures [39]. Media personnel/journalists should cover the pandemic adequately, but they should be judicious/ cautious to avoid over coverage. They should broadcast up to date facts using reliable information from respective health departments to remain a trusted source [18]. In addition, they should communicate with emphasis on useful and actionable information- They need to present story behind the numbers, what countries are doing to respond and highlight what individuals need to do. They should also avoid spread of misinformation and stigma which will encourage people to hide illness to avoid discrimination and prevent them from seeking healthcare and follow healthy behaviors. They should think about the heterogeneity of audience including vulnerable and innocent audience (e.g., adolescents, children, and suggestible readers). Media need to be sensitive and show empathy towards those affected and use simple, clear, and appropriate language [41]. They should offer practical information - e.g., relevant local telephone numbers for healthcare services or advice on handwashing with reference to trusted and up-to-date sources and broader governing bodies. They should only report the facts, with a genuine intent to expose the latest outbreak news as well as incorporate advice/ information coming from governing bodies and reliable experts. A wise consideration of what, for whom, how and when to communicate should guide the media.

Along with the responsibility of individual media personnel/ journalists, the role of the agencies governing and monitoring their activities cannot be overemphasized. To prevent unrealistic information spread on social media, it is necessary to coordinate the search for sources, identify and reduce their spread [42]. Social media giants can monitor high-traffic information and combine artificial intelligence to remove misleading or outdated information promptly [43]. Additional measures include educating public on indiscriminate dissemination of fake news as well as ensuring the availability of official sources of information from reputable academic institutions and other official public health agencies to allow verification of content [8]. For example, WHO has set up an information network for epidemics aimed at tackling the 'infodemic' by correcting and controlling the spread of false information in their 
myth buster segment [44]. Such global institutions should consider the dissemination of correct information in different languages, especially in developing countries.

\section{CONCLUSION}

list of responsibilities cannot be complete and will be

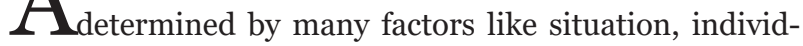
ual, and resources available for a particular place, time, and circumstance. Individualized decisions will have to consider the involved stakeholders (both self and others) as well as ethical principles like non-maleficence, beneficence, autonomy, confidentiality, and dignity. If we all play our respective roles, we will come through this period of challenge and will be in a better position to tackle future similar or even worse pandemics and adversities. Or, else, our ship will sink in the middle of this wave and hurricane!

\section{References}

I. World Health Organization. (2010, December II). Jakarta declaration on leading health promotion into the $2 \mathrm{I}$ st Century. Available from: https://www.who.int/healthpromotion/milestones_ ch4_20090916_en.pdf

2. Martinez-Palomo A. Social responsibility and health. In: ten Have $\mathrm{H}$, Jean MS, editors. The UNESCO universal declaration on bioethics and human rights: background, principles and application. Paris: UNESCO Publishing; 2009.p. 219-29.

3. Constitution of the World Health Organization. Geneva: World Health Organization. 1948. I.

4. Apressyan R, Balasubramaniam D, Carmi A, Castro L, Evans D, Gracia D, et.al. Bioethics core curriculum - section I. UNESCO Chair in Bioethics.2005; p. 56-59. Available from: https://unesdoc. unesco.org/ark:/48223/pf0000246885

5. Shakya DR, Singh RR, Shrestha RR. Bioethics for the welfare of the health service provider and consumer. Global Bioethics Enquiry. 20I5;3:55-62

6. Shakya DR, Thapa SB, Kar SK, Sharma V, Uchida N, Ortiz MR, et.al. COVID-19 across countries: situation and lessons for pandemic control. JBPKIHS. 2020;3(I):9-27. DOI: 10.3126/jbpkihs. v3il.303II

7. Shakya DR. Problems shared in Psychiatry help-line of a Teaching hospital in eastern Nepal during COVID-19 pandemic lockdown. Insights in Depress Anxiety. 2020;4:037-9. DOI: I0.29328/journal. ida. 1001017

8. Shakya DR, Mishra DR, Gyawali R, Rimal SP, Lama S,Yadav AK, et.al. COVID-I 9 pandemic and BPKIHS: our situation, endeavors and future direction. JBPKIHS. 2020;3(I):39-49. DOI: I0.3 I26/jbpkihs. v3il.30320

9. Piryani R, Piryani S, Piryani S, Shankar P, Shakya DR. Impact of COVID-19 pandemic on medical education: challenges and opportunities for medical educators in South Asia. JBPKIHS. 2020;3(I):28-38. DOI: 10.3 |26/jbpkihs.v3il.303।8

10. Piryani RM, Piryani S, Piryani S, Shakya DR, Huq M. COVID- 19 and Lockdown: Be logical in relaxing it.J Lumbini Med Coll. 2020;8(I): 4 pages. DOI: 10.22502/jlmc.v8il.36I

II. Piryani RM, Piryani S, Piryani S, Dangal G, Huq M, Shakya DR. COVID-19 testing: essential for tracking infection and helping authority to overcome the challenges of spread. Journal of Chitwan Medical College. 2020;10(2):90-2. DOI: 10.3126/jcmc. v10i2.29683

12. Shakya DR. Stress management- a way ahead. JBPKIHS. 2020;3(I): I-8. DOI: 10.3 I26/jbpkihs.v3il.303 I0

13. World Health Organization. Transmission of SARS-CoV-2: impli- cations for infection prevention precautions, Scientific brief, 2020. [Accessed on: 10 Jan 202I] Available from- https://www.who.int/ news-room/commentaries/detail/transmission-of-sars-cov-2-implications-for-infection-prevention-precautions

14. Centers for Disease Control and Prevention.COVID-19 overview and infection prevention and control priorities in non-US healthcare settings. [Accessed on 10 Jan 202I] Available from: https://www.cdc.gov/coronavirus/2019-ncov/hcp/non-us-settings/ overview/index.html

15. AlTakarli NS. China's response to the COVID-19 Outbreak: A Model for epidemic preparedness and management. Dubai Med J, 2020;3:44-9. DOI: 10.1 159/000508448

16. World Health Organization. Recommendations to member states to improve hand hygiene practices to help prevent the transmission of the COVID-I 9 virus, Interim guidance, I April 2020,World Health Organization IV.

17. World Health Organization. Cleaning and disinfection of environmental surfaces in the context of COVID-19, Interim guidance, 15 May 2020.

18. World Health Organization.COVID-19 Nepal: Preparedness and response plan (NPRP). Available from- https://www.who.int/docs/ default-source/nepal-documents/novel-coronavirus/covid-19-nepal-preparedness-and-response-plan-(nprp)-draft-april-9.pdf?sfvrsn=808a970a 2

19. World Health Organization. Coronavirus disease (COVID-19) outbreak: rights, roles and responsibilities of health workers, including key considerations for occupational safety and health: Available from- https://www.who.int/docs/default-source/coronaviruse/who-rights-roles-respon-hw-covid- 19.pdf?sfvrsn=bcabd40I_0

20. Shakya DR. Self care among health professionals. JBPKIHS. 2019;2(I): I-3. DOI: 10.3 I26/jbpkihs.v2i I.24959

2I. Shakya DR. Issue of Mental health at our work place. JBPKIHS. 20I8; I(I):I-4. DOI:I0.3 I26/jbpkihs.vliI.19746

22. Poudel K, Subedi P. Impact of COVID-19 pandemic on socioeconomic and mental health aspects in Nepal. International Journal of Social Psychiatry. 2020;66(8):748-55. DOI: I 0. I I 77/0020764020942247

23. Sharma S, Bhatta J. Public health challenges during the COVID-I9 outbreak in Nepal: a commentary. Journal of Health Research. 2020;34(4):373-6. DOI: I0.I I08/JHR-05-2020-0I 24

24. Shakya DR. Observation and lesson from psychiatry help-line of a teaching hospital in Eastern Nepal during COVID-19 pandemic lockdown. Clin Med. 2020;2(1):1021. 
25. Shakya DR. Health of our Future Health Professionals. JBPKIHS. 2019;2(2): I-3. DOI: I0.3 I26/jbpkihs.v2i2.27850

26. Paudel N. Citizens urged to be responsible to limit transmission of COVID-19.The Rising Nepal, National Daily, Monday, 24th August, 2020.

27. Mulmi R. COVID-19 doesn't kill, Ignorance kills! Swasthyakhabar Patrika, 24th August, 2020.

28. Thomas M. The Covid-19 responsibility we all own inside business. University of Melbourne, Pursuit, 3rd April 2020. Available from- https://pursuit.unimelb.edu.au/articles

29. Wendler WV. Individual responsibility and COVID-19. West Texas A \& M University, 24 August 2020. [Accessed on 9 Jan 2021] Available from-https://www.wtamu.edu/about/information/covid-19/ individual-responsibility-covid-19.html

30. Segall A. The sick role concept: understanding illness behavior. Journal of Health and Social Behavior, 1976;17(2):I63-70. DOI: 10.2307/2 I36342

31. Arekapudi S.A responsible patient.Virtual Mentor. 2003;5(4); I 123. DOI: I0.100I/virtualmentor.2003.5.4.pfor I-0304

32. Klompas M, Morris CA, Sinclair J, Pearson M, Shenoy ES. Universal masking in hospitals in the COVID-19 Era. N Engl J Med. 2020;382(2I):e63. DOI: 10.1056/NEJMp2006372

33. CDC guidelines, Healthcare facilities: Managing the operations during the COVID-19 pandemic, 22 Dec, 2020. Available fromhttps://www.cdc.gov/coronavirus/2019-ncov/hcp/guidance-hcf. html

34. Merchant RM, Lurie N. Social media and emergency preparedness in response to the novel coronavirus. JAMA. 2020;323(20):20I I-2 DOI: $10.1001 /$ jama.2020.4469

35. Schaffer ER.A review of the Werther effect and depictions of suicide: I 3 reasons why. UC Merced Undergraduate Research Journal, 20 I8; I 0(2): I - 19. DOI: 10.5070/m4 I 02038937

36. Tilak G. COVID-19: Role of media and issues faced by media. International Journal of Future Generation Communication and Networking. 2020;13(4):595-604.

37. Fernandez-Guerrero IM. WhatsAppitis. Lancet. 20I4;383(9922):1040. DOI: I0.10I6/S0I40-6736(|4)605I9-5.
38. Niederkrotenthaler T, Til B. Suicide and the media: from Werther to Papageno effects - a selective literature review. Suicidologi. 2019. 24(2): 4-12. DOI:10.5617/suicidologi.7398

39. D'Souza RS, D'Souza S, Strand N,Anderson A, Vogt MNP, Olatoye $O$.YouTube as a source of medical information on the novel coronavirus 2019 disease (COVID-19) pandemic. Glob Public Health. 2020;15(7):935-42. DOI: 10.1080/|744|692.2020.176| 426.

40. Depoux A, Martin S, Karafillakis E, Preet R, Wilder-Smith A, Larson $\mathrm{H}$. The pandemic of social media panic travels faster than the COVID-19 outbreak. J Travel Med. 2020;27(3):taaa03I. DOI: 10.1093/jtm/taaa03।

41. Powell M, Future Science Group. What role can the media play in managing the COVID-19 outbreak? [Accessed on 10 Jan 202I]. Available from- https://www.id-hub.com/2020/03/05/role-canmedia-play-managing-covid-19-outbreak/

42. Merchant RM. Evaluating the potential role of social media in preventive health care. JAMA. 2020;323(5):4I I-2. DOI: 10.100I/ jama.2019.21084.

43. Limaye RJ, Sauer M, Ali J, Bernstein J, Wahl B, Barnhill A, et al. Building trust while influencing online COVID-19 content in the social media world. Lancet Digit Health. 2020;2(6):e277-8. DOI: 10.1016/S2589-7500(20)30084-4.

44. Zarocostas J. How to fight an infodemic. Lancet. 2020;395(I0225):676. DOI: I0.10I6/S0 I40-6736(20)3046I-X. 